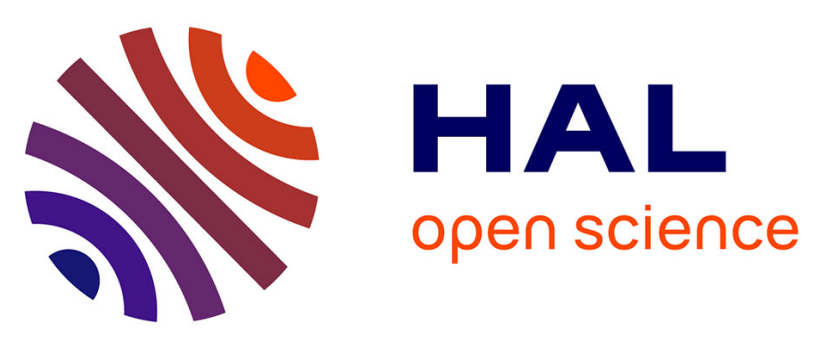

\title{
From individual communication to social networks: evolution of a technical platform for the elderly
}

Cécile Bothorel, Christophe Lohr, André Thépaut, Fabrice Bonnaud, Gilbert Cabasse

\section{- To cite this version:}

Cécile Bothorel, Christophe Lohr, André Thépaut, Fabrice Bonnaud, Gilbert Cabasse. From individual communication to social networks: evolution of a technical platform for the elderly. ICOST 2011: International Conference On Smart homes and health Telematics, Jun 2011, Montréal, Canada. pp.145-152, 10.1007/978-3-642-21535-3_19. hal-00609517

\section{HAL Id: hal-00609517 https://hal.science/hal-00609517}

Submitted on 19 Jul 2011

HAL is a multi-disciplinary open access archive for the deposit and dissemination of scientific research documents, whether they are published or not. The documents may come from teaching and research institutions in France or abroad, or from public or private research centers.
L'archive ouverte pluridisciplinaire HAL, est destinée au dépôt et à la diffusion de documents scientifiques de niveau recherche, publiés ou non, émanant des établissements d'enseignement et de recherche français ou étrangers, des laboratoires publics ou privés. 


\title{
From Individual Communication to Social Networks: Evolution of a Technical Platform for the Elderly
}

\author{
Cécile Bothorel ${ }^{1}$, Christophe Lohr ${ }^{1}$, André Thépaut ${ }^{1}$, \\ Fabrice Bonnaud $^{2}$, and Gilbert Cabasse ${ }^{2}$ \\ 1 Telecom Bretagne, UMR CNRS 3192 Lab-STICC, Technopôle Brest-Iroise CS \\ 83818, F-29238 Brest Cedex 3, France \\ firstname.lastname@telecom-bretagne.eu \\ 2 Alcatel-Lucent - Application Software Group - R\&D, 8 bis, rue de Kervezennec - \\ CS 82802, F-29228 Brest Cedex 2, France \\ firstname.lastname@alcatel-lucent.com
}

\begin{abstract}
One of the biggest challenges we currently face is to keep elderly people immersed in their social environment when they leave their home and enter a retirement home. Many of them feel isolated. The TV stands as their favorite media, and our first experiments showed that listening to vocalized local news and receiving TV messages and photos from family helped in fighting these feelings of isolation. With online social networks, we wish to involve the elderly in new types of interactions, more various and frequent. They will be more active and included in micro-conversations around multimedia contents. The retirement homes will benefit also from social networking capabilities. They will participate to the local news dedicated to the elderly people. In addition, the remote family will be informed of activities through an agenda and various publications.
\end{abstract}

Keywords: Social Ties; Social Networks; Digital Life; Assistive Technology to Improve Quality of Life and Health for Seniors and their Caregivers; Platforms, Middleware and Software Architectures for Seniors; Real World Deployments and Experimentations in Smart Houses, Hospitals \& Living communities.

\section{Introduction}

The aging population is a very strong concern in Western countries. The significant increase in life expectancy leads to worry about increasing the quality of life of seniors. On the other hand, there is a strong link between aging and loneliness. This sentiment characterizes persons who do not communicate with their family and immediate friends, and whose number of social contacts decreased significantly. According to French statistic:1, $74 \%$ of elderly people in France say they are suffering from loneliness.

\footnotetext{
${ }^{1}$ From the group "Combattre la solitude" (Fight loneliness) which includes many
} associations and the Fondation de France 
If several other factors reinforce this feeling of loneliness (physical disabilities that limit the territory of life of elderly, loss of spouse, etc.) [7, the loss of a social network is especially noticed. This phenomenon is observed when work colleagues are encountered less often, when friends are more remote or die, when family visits are becoming less frequent. Several studies [4] show that the loss of a spouse (only one in five seniors lives together as a couple) also accelerates social isolation. Finally it is estimated that currently one quarter of residents in nursing homes might not suffer from physical dependence or psychological dependence, but from social dependence. Through technical platforms suitable and customizable, our multidisciplinary research team aims at improving the lives of the elderly living in retirement homes by preserving, enhancing, or creating social ties. Digital innovation is a huge issue nowadays to enhance the quality of life, autonomy or social life for elderly [8].

TV-Kiosk 2, very similar to our project, uses a simple Internet service, where "elderly can now stay in touch with their family and friends and get easy access to information provided by the care centre they life in. [...] A small-scale field trial is ongoing". Related works are still new studies, and eHealth techno-enthusiasts have still to evaluate socio-technical factors to maximise the likelihood of successful implementation and adoption [2].

Through the AIPA project (2007-2010)3, we propose a TV-based service that allows elderly people living in nursing homes to be connected to their network of contacts. The project team has chosen to involve several players (seniors, families, professionals of the nursing home, retired volunteers, neighbourhood town hall, etc.) since the beginning of the design process. Sociologists have conducted individual and group interviews and have identified two types of services: the elderly receive emails, pictures, videos from their relatives, and also local news and obituaries from the regional daily press [3].

Sociologists also recruited 11 elderly people (aged 59 to 92 , median age is 87 ), and their 65 relatives. These people have experimented the service for about a year. 3 of them did not much use it; 4 gave up. The 4 daily active participants were mostly people in good health with few visits from the caregivers. They were elderly people less visited by their family but with a strong emotional network and they enjoyed particularly getting news from their family through AIPA mediated services. While most of the users have shown a real interest, they expressed some suggestions for improvement. The socially active users felt a frustration because of their position as consumers; they asked for more active functionalities such as the capability to respond to the messages or comment on pictures sent by their relatives. Emotionally isolated people or people whose family was minimally involved, showed less enthusiasm for AIPA since the proposed contents were essentially social. The the other contents were much poorer. They asked for thematical contents or contents related to their hobbies.

\footnotetext{
2 http://www.smartcareplatform.eu/content/tv-kiosk

3 Companymages/AIPA Project Home Page. https://www. companymages .eu, last visited January 2011.
} 


\section{Social Networks and New Challenges for Isolated People}

\subsection{Strengthen and Rediscover Relationships}

Social studies show that virtual friendships are mostly the prolongation of real life ones. In general, people who interact in their virtual life also interact in their real life [6] [5. People involved in many social activities will be very active online. We think in our current project Mazadoo that with new networking possibilities in AIPA-like systems we could interest such socially active old people. Beyond this standard behaviour, we find people who make new connections on the web before meeting in real life. For those individuals the aim of being online is first to share interests, passions, and not to extend their network just to extend it as a primary objective [6]. The emotionally isolated people identified in the AIPA study may be candidates to share knowledge, stories, passions, etc and maybe rediscover relationships through mediated networking.

We cannot talk about online social networks without focusing on Facebook usage. [1] observed that even if the average number of friends is around 130, most people interact regularly with 4 to 6 people. These few friends are considered as strong ties and are mostly people we meet often in real life. Social networks have changed some aspects of our weak tie relationships. Weak ties are unfrequent relationships with known people, such as old school mates. "In the past we would have to meet or phone them to catch up. Now, the social networks open an easy route to reconnect to them. Via newsfeeds and their wall, we can get back in touch in a lightweight manner. Although weak ties are much bigger in number, communication with them is unfrequent".

By introducing Social Networking Platforms (SNP) in our project, we aim at strengthening existing and close relationships for high sociable people, but also rediscover weak ties and develop hobby-oriented ties especially for those who feel isolated and are not involved in a real-life dense network. For the first ones, the web2.0 networking tools will bring a lot of (maybe light but frequent) exchanges; for the second ones, the tools will open the opportunity to create links with 'old' relationships or 'new' ones in relation with centres of interest.

\subsection{From Point-to-Point Messaging to Community Interactions}

In AIPA, family (and acquaintances) shared emails and photos through a dedicated service developed for this purpose in the project. Each member of the family shared his/her content with one older people. The elderly is the recipient, the family is the sender, with no mediated-interaction around a photo. But the elderly, as a matter of fact (see previous section), is asking conversing about a photo, about a message or about a video.

The contextual comments to a content is one of the signatures of SNPs. The publication of a photo (and its legend) becomes the scene of real feeds of reactions. People don't send content anymore as an attachment, but now publish them to a public (the public may be constrained and limited to a few friends). As blog posts, those publications are now a way to bring together people who 
interact as micro- and transient-communities; incidentally we observed that the published content becomes sometimes more an opportunity to meet friends than to collect comments about it.

Social networking appears as an interesting opportunity to keep elderly people involved in social interactions. Just like casual discussions at the baker's or when walking to the marketplace, social networking allows frequent, light and collective discussions with close family, but also with other people commenting on a photo or a web link.

\section{Mazadoo: A Social Network to Connect Elderly People}

The dedicated service provided by AIPA is quite simple to use, but the family has to subscribe, manage new credentials, upload their photos to this dedicated site, etc. It's expensive and time-consuming to manage several image repositories.

Now, with the SNPs, e.g. Facebook, those sharing activities are easy and popular. In Mazadoo, we make the hypothesis that most relatives involved in our experiments will know and be regular users of social medias. We find that at the very first stage of the experiments, they actually are using Facebook. We hope that they will more easily and more often interact with their elderly family. We also hope that new participants will naturally become involved (nieces, cousins, grand-children, etc.).

\subsection{Why is Mazadoo Using Facebook?}

The aim of Mazadoo is to offer a link between people using a social network to communicate (with the computer interface proposed by the social network editor) and elderly people, who should be able to receive and respond from the social network, but using the Mazadoo TV interface. From the standpoint of the elderly, the underlying SNP is transparent. In fact, Mazadoo could be interfaced with any SNP.

Why the choice of Facebook against the competitors (Google, Twitter...)? From a technical point of view, the SNP must provide an open API in order for the Mazadoo platform to retrieve the interactions (messages, pictures, videos...) posted by the external users and inversely insert new interactions toward relatives on behalf of the elderly. The SNP should preferably offer a single tool to the relatives to support multiple interaction types (text, picture, video): send a private interaction to the elderly (like an email), send an interaction to a group of friends, including the elderly (like when you post on your Facebook wall), allow the friends to add comments to the contributions from others and provide some calendar functionalities (send an appointment to the elderly). The access to the SNP should be free, at least for the relatives. The SNP should also preferably be already known - and used - by a large audience of relatives. This indeed increases the possibility to get support from other relatives (children...), and thus accelerating the learning curve for using that platform. Retirement homes may also use the same SNP to communicate with the general public (and thus include 
the elderly, their relatives, and any external people interested in the activities), via a global page for the retirement home information.

Facebook is currently the only platform to respond positively to all those considerations. This also overcomes the only drawback of Facebook: its bad reputation about privacy disclosure. This reputation is based on cases that happened with Facebook accounts that are using the default privacy settings, which allow strangers to see your contributions. Mazadoo creates the Facebook accounts on behalf of the elderly, and tunes the privacy settings so that only friends can see their contributions. We gave courses to educate the family on these settings.

But Facebook is also THE social network: when you speak of social networks, the first platform that comes to mind is Facebook. Plugging Mazadoo into the favorite network of the end users makes it immediately usable by 600 million users worldwide. This predominent position of Facebook in the social networks also allows Mazadoo the benefit of a new information media: the Facebook pages. Facebook contains millions of pages about specific subjects that can be in the interests of the elderly: their favorite soap opera, their native village, a club for their hobby, the sport club or the school of their grandchildren, etc. This feature brings potential news hobbies to the ederly (not possible within AIPA).

\subsection{The Services Provided by Mazadoo}

These services can be split into two categories: personal services, provided in the room of the resident; and common services for all the residents of the retirement home such as common activities proposed by the coordinator of socio-cultural activities.

Individual Services. Using the remote control of the TV, the elderly channelflicks to the Mazadoo channel. This is a personal channel that provides, like a Facebook newsfeed, in a single screen, an adapted access to a set of services: messages from relatives, photo/video sharing from Facebook friends; reminders of activities proposed in the retirement home, via an interactive agenda from the retirement home Facebook page; a daily selection of videos, pictures and articles from local press (The Telegramme, a regional newspaper); and, in the near future, contents about their hobbies from Facebook pages.

Communication via social network friends. The elderly person have a personal Facebook account. Relatives, as friends, benefit from all the usual Facebook features to communicate to the elderly : sharing status, pictures, videos (except links that cannot be adapted to Mazadoo); sending messages to all their friends including the elderly or private message to the elderly only. These interactions can be performed on a nomadic mode from anywhere (browser, smartphone). Some people (in particular teenagers) say that they never share with their parents or grand-parents what they share with their Facebook friends. This restriction is also true between private life and professional life. This multiple profile management is one of the issues we are working on. 


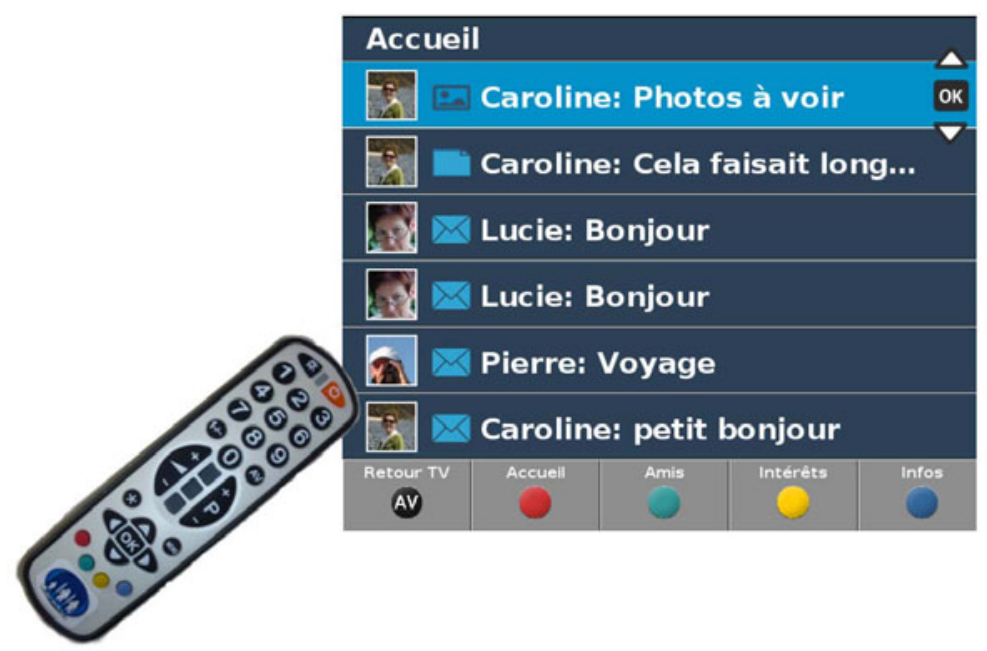

Fig. 1. Facebook news feed on TV

Adaptation. Obviously, the native Facebook web page cannot be read by the elderly on their TV screen. Mazadoo ergonomists and sociologists work with a representative panel of users to define the most adapted display of Facebook newsfeeds and content consultation. When the elderly channel-flicks to their Mazadoo channel, an adapted display of the newsfeed of her/his Facebook account, enriched with private messages, is provided. This homepage (Fig 11) lists the latest received messages, pictures or videos, prefixed with the sender's profile picture. Because a TV screen is not adapted for the elderly to read a long text, all textual contents such as messages, comments or articles are vocalized (read by the TV through the Text-To-Speech technology).

Interaction. The elderly are not passive when receiving messages, pictures or videos. They can select the Like this button with the remote control. This action updates the Facebook content by adding the elderly to the list of people who like this item. For more interaction, the elderly can respond/comment by using the telephone to record a voice mail. By selecting the Respond button with the remote control, the phone rings and proposes to record a voice mail. The voice mail is seen as a link to an audio file and inserted as a comment to the original Facebook content.

Common services. One requirement of a retirement home is to provide visibility on their services (e.g. activities, meal menus) to visitors but also to remote family who are often also the payer. To fit this need, a Facebook page for the retirement home has been created: it compiles pictures and testimonies of activities, agenda for future events, comments, questions, etc. It can be consulted by people who say they fan. 
Considering this agenda, Mazadoo enriched Facebook by providing to the retirement home coordinator the record of a reminder of an activity. This reminder is a voice message that is played to residents minutes before the activity. The phone rings and the message is played. A TV screen in the welcome hall of the retirement home displays a mosaic of contents automatically when dynamically extracted from the retirement home Facebook page. Visitors and residents have access to up-to-date meal menus, upcoming activities, pictures from previous events, etc.

\subsection{Experimentation}

Technical aspects. The Mazadoo architecture is based on cloud computing. Mazadoo services are provided by software running on servers, called the Mazadoo platform, hosted on the ImaginLab4 data center. To minimize the number of servers, virtualization is performed. This single shared platform provides homogeneous services to two different retirement homes, located in different counties. It means that no servers are installed in retirement homes.

The Mazadoo platform, based on an Alcatel-Lucent solution, is a SIP powered infrastructure which provides: Voice and video Real time IP Communication, Unified messaging (text or voice messages deposit, notification and consultation), Text-to-Speech, conferencing, openness through standard XML Web Services for application development but also through the standard SIP protocol to support devices such as a Set Top Box. Mazadoo application is developed on top of this XML Web Service API. Users' devices are connected to the platform using SIP protocol. The Mazadoo application collects Facebook contents, aggregates and adapts them.

Participants. The 4 active volunteers plus 2 out of the 3 idle volunteers of our previous AIPA project have accepted to continue with the experiment of Mazadoo. Additionally Mazadoo is deployed in a second retirement home where 6 elderly have been recruited with 26 of their relatives. 6 other elderly persons interested in Mazadoo are to be enrolled. Sociologists and ergonoms are following the experiment and help in adapting Mazadoo to the observed usage. They closely follow the elderly and help them in learning how to use the system.

\section{Conclusion}

This paper describes a technical platform dedicated to the elderly in retirement homes. The goal is to offer services to preserve, enhance, or create social ties. The

\footnotetext{
${ }^{4}$ ImaginLab is the very first platform in France to provide both hosted ICT technologies and a panel of users called the imaginers. ImaginLab data center provides services, such as Mazadoo, a panel of users through a very high speed internet connection based on FTTH (Fiber to The Home) and FTTB (Fiber To The Building) at 100 Mbps. More info on ImaginLab: http://vimeo.com/15623507, http://imaginlab.fr/blog-en/
} 
last evolution of the project Mazadoo has lead to new services belonging to the web 2.0 area. Elderly people are now connected to Facebook. For acceptability reasons, services are accessed via TV, remote control and phone. The elderly can receive messages (text, pictures, and videos) from their contacts, access to local news, check the calendar of the retirement home activities, etc. Moreover, they can now react to content, and post voice mail comments via their phone. This extends their cloud of friends.

The project is conducted by a multidisciplinary team composed of industrialworkers, academics, engineers, ergonoms and sociologists. The prototype is deployed, installed in the individual rooms, and tested by some real users from two selected retirement homes. The professionals showed a strong interest and are opening Facebook pages for their institution to show activities and publications to the remote families, and also add agenda entries to the elderly peoples' newsfeeds. The cities involved are also animating Facebook content and communities. We are conducting interviews and usage studies since the end of the project.

Futures are now to add services such as: hobbies (accessing Facebook pages selected through preferences profile), social games, etc.

Acknowledgments. The project participants wish to thank the staff of the residences of Kerlevenez (Brest, France) and Saint-Anne (Lannion, France), elderly volunteers and their families. Mazadoo project is supported by the French Media and Network Cluster (Pôle de compétitivité Images et Réseaux) and the French Governement (Direction Générale des Entreprises).

\section{References}

1. Adams, P.: Senior user experience researcher at google. Presentation at Voices That Matter Web Design Conference, San Francisco (June 2010)

2. Black, A.D., Car, J., Pagliari, C., Anandan, C., Cresswell, K., Bokun, T., McKinstry, B., Procter, R., Majeed, A., Sheikh, A.: The impact of ehealth on the quality and safety of health care: A systematic overview. PLoS Med. 8(1), e1000387 (2011)

3. Bonnaud, F., Segarra, M.T., Le Moan, C., Thépaut, A., Kerdreux, J.: Companymages/AIPA: offering communication and comfort services to the aged in institution. In: Aged Cared Informatics Symposium. INFO - Dépt. Informatique (Institut Télécom-Télécom Bretagne), Bell Labs, Alcatel Lucent (2009)

4. INSEE: Enquête relations de la vie quotidienne et isolement. EPCV (1997)

5. Lampe, C., Ellison, N.B., Steinfield, C.: Changes in use and perception of facebook. In: Proceedings of the 2008 ACM Conference on Computer Supported Cooperative Work. CSCW 2008, pp. 721-730. ACM, New York (2008), http://doi.acm.org/10.1145/1460563.1460675

6. Lethiais, V., Roudaut, K.: Les amitiés virtuelles dans la vie réelle: profil, motifs et modalités de construction. RéSeaux: Communication, Technologie, Société (164), 13-49 (2010)

7. Pitaud, P.: Responding to dependency in old age. Bold, Journal of the International Institute on Ageing (United Nations - Malta) 20(3), 9-14 (2010)

8. Rivière, C.A., Brugière, A.: Bien vieillir grâce au numérique. Fing (2010) 